\title{
Proof of concept for molecular velcro based on the attractive interaction between porphyrin and pyridine containing copolymers
}

\author{
M. Sievers, J. C. Namyslo, F. Lederle, E. G. Hübner* \\ Institute of Organic Chemistry, Clausthal University of Technology, Leibnizstr. 6, DE-38678 Clausthal-Zellerfeld, Germany
}

Received 3 November 2017; accepted in revised form 24 January 2018

\begin{abstract}
In this short communication, we investigated the synthesis and mixing of porphyrin and pyridine functionalized copolymers as a proof of concept for a velcro-like interaction. A functionalized porphyrin monomer with one polymerizable side chain was synthesized following a rational synthetic pathway. Subsequent copolymerization and careful removal of residual free porphyrin led to poly(n-butyl acrylate-co-5,10,15-triphenyl-20-(3-vinylphenyl)porphyrin). The immobilized porphyrin was transformed into the corresponding zinc(II) complex, which is capable of the coordinative binding of one pyridine moiety. Complete metallation was proven by absorption spectroscopy. 4-Vinylpyridine was immobilized by copolymerization with $n$-butyl acrylate, too. Via controlled radical polymerization conditions, the molecular weight of poly $(n$-butyl acrylate-co-4-vinylpyridine) was limited to one tenth of the molecular weight of the porphyrin containing copolymer. This large difference in the molecular weight easily allowed identifying the polymers in the mixture of both. With the help of diffusion ordered nuclear magnetic resonance spectroscopy, the complete and temperature-stable precipitation of the porphyrin containing copolymer was observed, proving the expected attractive interaction and supramolecular network formation.
\end{abstract}

Keywords: polymer synthesis, molecular engineering, supramolecular polymers, immobilized porphyrins, selective interaction

\section{Introduction}

Structured materials from nature have been a great model for functionalized materials in various cases. Typical examples are the osage orange tree as template for barbed wire, the lotus plant as model for water repellent surfaces and burdock as natural example for hook-and-loop fasteners, commonly known as velcro. The latter is realized on a molecular scale by nature, too, leading to functionalized materials with unique adhesive properties in some cases. The most popular example for a velcro-like connectivity is probably double stranded deoxyribonucleic acid (DNA) with a selective non-covalent hydrogen bonding between both strands. Bacteria use a velcrolike adhesive interaction to bind their biofilm onto surfaces [1]. Some sort of 'molecular velcro' has been described for peptides, which self-assemble on surfaces and subsequently bind to the surface by (usually irreversible) covalent bonds [2]. A true velcrolike behaviour has been described for polymer brushes in tendon fibrils [3]. The binding of the catechol moiety of L-3,4-dihydroxyphenylalanine (LDOPA) onto surfaces used by marine mussels is probably the most known example for underwater adhesives $[4,5]$. Consequently, copolymers containing catechol side chains have shown to exhibit strong adhesive interactions [5]. It has to be noted, that in these cases irreversible binding towards the surface and irreversible curing of the polymer by crosslinking play an important role beyond a velcro-like interaction. Some purely synthetic approaches have been performed to mimic velcro-like interactions on a 
molecular scale. One of the first concepts is based on block-copolymers to improve the attractive interaction at the interface of immiscible polymer blends [6]. The binding of a crosslinked polymer matrix with grafted polymer chains via entanglements picks up the idea of reversibly bound surfaces by interactions on an molecular level [7]. Based on selective hostguest interactions, more sophisticated molecular counterparts of the both components of hook-andloop fasteners have been created. Polyacrylamide gels functionalized with cyclodextrin as host have shown a strong binding towards polyacrylamide gels functionalized with adamantane and other nonpolar moieties as guest molecule on a macroscopic level [8]. Comparable cyclodextrin-adamantyl complexation, as well as selective peptide interactions, have been used for the patterned immobilization of vesicles and liposomes on surfaces [9]. The host-guest interaction of cucurbit[7]uril with ferrocene, both immobilized in a polyethyleneimine matrix grafted onto silicon, has been used to obtain two functionalized silicon surfaces which act as reversibly binding velcro on a molecular scale and provide strong underwater adhesion [10]. The interaction of immobilized ferrocene with immobilized cyclodextrin has been used to synthesize crosslinked polyionic membranes which show a strong adhesion towards each other [11]. Overall, only very few systems suitable for molecular velcro are known. As part of our work on molecular polymer structures $[12,13]$, herein we investigated the synthesis and intermixing of metalloporphyrin containing polymers with pyridine containing polymers based on $n$-butyl acrylate with regard to an attractive velcro-like supramolecular interaction (Figure 1).

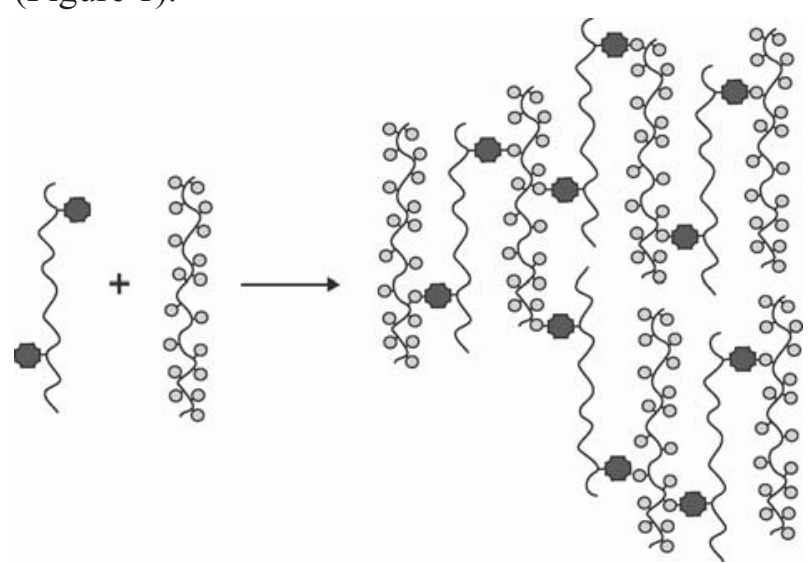

Figure 1. Sketch of supramolecular network formation by coordination of copolymers containing pyridine (light grey circle) to copolymers containing metalloporphyrins (dark grey)
Metalloporphyrin containing polymers are wellknown in literature and have been synthesized for various reasons. Due to their activity as photosensitizer, porphyrins have been immobilized on insoluble and crosslinked polymer resins $[14,15]$. Obtaining non-crosslinked and soluble copolymers with porphyrins is more complex. While monomers derived from tetraphenylporphyrin (TPP) functionalized with four polymerizable substituents are easy to achieve, the polymerization can only be carried out at low amounts of the porphyrin and low conversion to prevent crosslinking by the multifunctional porphyrin monomer [16]. As a consequence, the copolymers frequently contain a statistical amount of porphyrin which is significantly below one porphyrin unit per polymer chain. A comparable problem arises in the case of the postfunctionalization of soluble polymer chains with tetrafunctionalized porphyrins. To prevent crosslinking during the functionalization step, low concentrations of the porphyrins have to be applied [17]. The copolymerization with monofunctionalized TPP derivatives overcomes these problems. Unfortunately, the first step of the synthesis of these derivatives following the standard TPP synthesis out of benzaldehyde and pyrrole $[18,19]$, but with a mixture of benzaldehyde and a second functionalized benzaldehyde such as $p$-nitrobenzaldehyde or $p$-1hydroxyethylbenzaldehyde and other combinations, leads to a mixture of the unsubstituted, mono, cis- and trans-bis, tris as well as tetrakis functionalized porphyrin which needs to be separated. Consequently, the resulting yields are low and usually in the range of $2-4 \%$ [20-22] although slightly higher yields are seldomly reported $[23,24]$. The careful separation, potentially by repetitive column chromatography, of higher functionalized derivatives [22] is a crucial step, since each of them would act as a crosslinking reagent.

Fortunately, rather recently elegant synthetic routes towards selectively substituted porphyrins have been published [25-27]. Especially the synthetic pathway developed by Lindsey has proven to be extremely versatile and applicable for various functional groups such as ethynyl, pyridyl, halogeno and other functionalities [22, 25, 26, 28, 29].

\section{Experimental part}

\subsection{Equipment and materials}

All air-sensitive operations were performed at a high vacuum line using Schlenk techniques. If not noted 
differently, chemicals were bought from SigmaAldrich (Sigma-Aldrich Chemie GmbH, Munich, Germany). 2,2'-Azobis(2-methylpropionitrile) (AIBN) was recrystallized from dry ethanol and dried in high vacuo before use. Dichloromethane (DCM) and toluene were passed through a PS-MD-4 solvent purification system (Inert Corporation, Amesbury, MA, United States) for drying $\left(<10 \mathrm{ppm} \mathrm{H}_{2} \mathrm{O}\right)$. 4-Vinylpyridine and triethylamine were degassed, dried with $\mathrm{CaH}_{2}$ over night and distilled before use. $n$-Butyl acrylate was washed with $\mathrm{NaOH}(4 \mathrm{wt} \%)$ and water, dried with $\mathrm{CaCl}_{2}$ and freshly distilled before use. Pyrrole (abcr GmbH, Karlsruhe, Germany) was freshly distilled before use. 3-Vinylbenzaldehyde, acetic acid, chloroform, deuterated chloroform (Deutero $\mathrm{GmbH}$, Kastellaun, Germany), trifluoroacetic acid, 2,3-dichloro-5,6-dicyano-1,4-benzoquinone (DDQ), 2-(ethoxycarbonyl)-2-propyldithiobenzoate and $\mathrm{Zn}(\mathrm{OAc})_{2}$ have been used as received. 2,2'-Phenylmethylene-bis(5-(hydroxyphenylmethyl)- $1 H$-pyrrole) (1) $[25,26,30]$, tetraphenylporphyrin (TPP) [18] and the zinc(II) complex thereof (TPP-Zn) [31] have been synthesized according to literature.

A Heraeus Labofuge 400R (ThermoFisher Scientific Messtechnik GmbH, Oberhausen, Germany) was used for centrifugation at $4500 \mathrm{rpm}$. Elemental analyses were performed with a Vario EL system (Elementar Analysensysteme GmbH, Langenselbold, Germany). Infrared (IR) spectra were recorded on an Alpha-T FT-IR spectrometer (Bruker Corporation, Billerica, MA, United States) equipped with a Platinum diamond-ATR unit. Ultraviolet-visible (UV/Vis) absorbance spectra were recorded on a V650 (Jasco Germany GmbH, Gross-Umstadt, Germany) UV-Vis spectrophotometer. For electron impact (EI) ionization mass spectra, a 320 MS TQ (Agilent Technologies, Inc., Santa Clara, CA, United States) mass spectrometer and for electrospray ionization (ESI) mass spectra a 1100 Series (Hewlett-Packard/Agilent Technologies, Inc., Santa Clara, CA, United States) LC/MS mass spectrometer were used. Size exclusion chromatography (SEC) measurements were carried out with a Waters 515 HPLC pump (Waters GmbH, Eschborn, Germany) and a Knauer Smartline RI 2300 detector (Knauer Wissenschaftliche Geräte GmbH, Berlin, Germany). For low molecular weight samples, 1 Ultrastyragel 100 A, 2 Ultrastyragel 200 A from Waters $\mathrm{GmbH}$ and 1 Oligopore column from Polymer Laboratories (Agilent Technologies, Inc., Santa Clara, CA, United States) were used. For high molecular weight samples, 4 mixed-A columns from Polymer Laboratories were used. Tetrahydrofuran (THF) with a flow rate of $1 \mathrm{~mL} \cdot \mathrm{min}^{-1}$ at $25^{\circ} \mathrm{C}$ was used as eluent. Molecular weights were obtained relative to polystyrene calibration. All molecular weights are referenced relative to poly( $n$-butyl acrylate) according to the universal calibration with Mark-Houwink coefficients given in literature $\left(K_{\mathrm{PS}}=11.4 \cdot 10^{-5} \mathrm{dL} \cdot \mathrm{g}^{-1}\right.$, $\alpha_{\mathrm{PS}}=0.716, K_{\mathrm{PBA}}=12.2 \cdot 10^{-5} \mathrm{dL} \cdot \mathrm{g}^{-1}$ and $\alpha_{\mathrm{PBA}}=$ 0.765) [32]. Nuclear magnetic resonance (NMR) spectra have been recorded on a Bruker Avance 400 (400 MHz $\left({ }^{1} \mathrm{H}\right), 100 \mathrm{MHz}\left({ }^{13} \mathrm{C}\right)$ ) and Avance III 600 $\left(600 \mathrm{MHz}\left({ }^{1} \mathrm{H}\right), 150 \mathrm{MHz}\left({ }^{13} \mathrm{C}\right)\right)$ FT-NMR spectrometer (Bruker Corporation, Billerica, MA, United States). Chemical shifts are given in ppm relative to the residual solvent signal. Diffusion ordered NMR spectroscopy (DOSY) data were recorded on the Bruker Avance III 600 spectrometer equipped with a broad band observed (BBO) probe with $z$-Gradient. The spectrometer was additionally provided with the NMR thermometer hardware (Bruker Corporation) that ensured highly stable temperature conditions. Calibration of the gradient strength $G$ was conducted by means of a deuterium oxide sample containing $\mathrm{H}_{2} \mathrm{O}$-traces and was found to be $0.548 \mathrm{~T} \cdot \mathrm{m}^{-1}$ for the $\mathrm{BBO}$ probe, respectively. The diffusion ordered spectra were performed in $3 \mathrm{~mm}$ NMR tubes Wilmad 335 (Wilmad-LabGlass, Vineland, NJ, United States) under calibrated (methanol thermometer) and carefully stabilized temperature conditions, i.e. $T=$ $298 \pm 0.1 \mathrm{~K}$. The probe head nitrogen gas flow was adjusted to $800 \mathrm{~L} \cdot \mathrm{h}^{-1}$. Optimized pulse repetition delays $\left(d_{1}=10 \mathrm{~s}\right)$ were obtained from inversion-recovery experiments. Sample spinning was used in order to avoid convection. The applied pulse sequence was the DOSY Oneshot experiment creating a series of $161-D$ spectra with squared increase of the gradient field strength from 10 to $80 \%$ [33]. The intergradient delay (diffusion time) $\Delta\left(d_{20}\right)$ was set to $0.25 \mathrm{~s}$. The corresponding length of the gradient pulse $(\mathrm{p} 30 ; \delta / 2)$ was adjusted to $2.0 \mathrm{~ms}$. Each single spectrum was processed with a line-broadening factor (LB) of $1.0 \mathrm{~Hz}$. The DOSY data were analyzed with the DOSY Toolbox in order to calculate diffusion coefficients and generate the common DOSY plot [34]. A viscosity of $0.538 \cdot 10^{-3} \mathrm{~Pa} \cdot \mathrm{s}\left(25^{\circ} \mathrm{C}\right)$ for $\mathrm{CDCl}_{3}$ has been used for the calculation of the hydrodynamic radii [35].

Restricted and unrestricted density-functional theory (DFT)-calculations were carried out by using the 
Jaguar 9.1.013 software (Schrodinger, Inc., New York, NY, United States) [36] running on Linux 2.6.18238.el5 SMP (x86_64) on five AMD Phenom II X6 1090T processor workstations (Beowulf-cluster) parallelized with OpenMPI. Molecular Mechanics (MM2) optimized structures were used as starting geometries. Complete geometry optimizations were carried out on the LACVP* (Hay-Wadt effective core potential (ECP) basis on heavy atoms, N31G6* for all other atoms) basis set and with the hybrid PBE0 density functional. All calculated structures were proven to be true minima by the absence of imaginary frequencies. Plots were obtained using Maestro 10.5.013, the graphical interface of Jaguar.

\subsection{Synthesis of}

3-(bis(1H-pyrrol-2-yl)methyl)styrene (2)

A round-bottom Schlenk flask equipped with a magnetic stirring bar was evacuated, heated and backfilled with nitrogen several times. The flask was charged with freshly distilled pyrrole $(13.09 \mathrm{~mL}$, $12.70 \mathrm{~g}, \quad 0.19 \mathrm{~mol})$ and 3-vinylbenzaldehyde $(0.96 \mathrm{~mL}, 1.00 \mathrm{~g}, 7.57 \mathrm{mmol})$. The reaction was started by addition of trifluoroacetic acid $(74 \mu \mathrm{L}, 0.11 \mathrm{~g}$, $0.97 \mathrm{mmol}$ ). After stirring for $5 \mathrm{~min}$ at ambient temperature, the reaction was stopped by addition of $0.1 \mathrm{M}$ aqueous $\mathrm{KOH}(10 \mathrm{~mL})$. Ethyl acetate $(50 \mathrm{~mL})$ was added to the black solution, the organic phase was washed with water $(2 \times 50 \mathrm{~mL})$ and dried over $\mathrm{Na}_{2} \mathrm{SO}_{4}$. After removal of the solvents in vacuo, the oily residue was purified by column chromatography (hexane: DCM 6:1 v/v, $\left.R_{\mathrm{f}}=0.15\right)$. After removal of the solvent, 2 was received as viscous liquid. Yield: $1.01 \mathrm{~g}$ $(54 \%)$.

${ }^{1} \mathrm{H}-\mathrm{NMR}\left(600 \mathrm{MHz}, \mathrm{CDCl}_{3}\right): \delta=5.22(\mathrm{dd}, J=10.7$, $0.8 \mathrm{~Hz}, 1 \mathrm{H}, \mathrm{H}-19 \mathrm{a}), 5.44$ (s, 1H, H-1), 5.70 (dd, $J=$ 17.7, $0.8 \mathrm{~Hz}, 1 \mathrm{H}, \mathrm{H}-19 \mathrm{~b}), 5.90-5.93$ (m, 2H, H-10 $+\mathrm{H}-14), 6.15(\mathrm{dd}, J=5.8,2.9 \mathrm{~Hz}, 2 \mathrm{H}, \mathrm{H}-11+\mathrm{H}-15)$, 6.61-6.71 (m, 2H, H-12+ H-16), 6.66 (dd, $J=17.7$, $10.7 \mathrm{~Hz}, 1 \mathrm{H}, \mathrm{H}-18), 7.06-7.11$ (m, 1H, H-9), 7.217.34 (m, 3H, H-5 + H-8 + H-7), 7.88 (br. s, 2H, H-13 $+\mathrm{H}-17) \mathrm{ppm} ;{ }^{13} \mathrm{C}-\mathrm{NMR}\left(150 \mathrm{MHz}, \mathrm{CDCl}_{3}\right): \delta=$ 44.0 (1C, C-1), 107.3 (2C, C-10 + C-14), 108.5 (2C, C-11 + C-15), 114.2 (1C, C-19), 117.3 (2C, C-12 + C-16), 124.8 (1C, C-7), 126.5 (1C, C-5), 127.9 (1C, C-9), 128.9 (1C, C-8), 132.4 (2C, C-2 + C-3), 136.7 (1C, C-18), 138.0 (1C, C-6), 142.4 (1C, C-4) ppm; IR (ATR): 3485-3218, 3086, 3007, 2979, 2858, 1627, 1598, 1578, 1557, 1480, 1464, 1418, 1400, 1373, 1292, 1254, 1112, 1087, 1026, 990, 970, 908,
$883,811,767,755,711,664,647,611,607,556$, 546, $541 \mathrm{~cm}^{-1}$; ESI-MS: $m / z[\%]=247(100)$ $[\mathrm{M}-2 \mathrm{H}+\mathrm{H}]^{+}, 182$ (46) $[\mathrm{M}-\text { pyrrole }]^{+}$. HRMS: $\mathrm{MH}^{+}$, found: $249.1390 . \mathrm{C}_{17} \mathrm{H}_{17} \mathrm{~N}_{2}$ requires 249.1392 .

\subsection{Synthesis of 5,10,15-triphenyl-20- (3-vinylphenyl)porphyrin (3)}

A round-bottom $S c h l e n k$ flask equipped with a magnetic stirring bar was evacuated, heated and backfilled with nitrogen several times. The flask was charged with 2,2'-phenylmethylene-bis(5-(hydroxyphenylmethyl)-1 $H$-pyrrole) (1) (1.00 g, $2.30 \mathrm{mmol})$, $m$-(bis(1H-pyrrol-2-yl)methyl)styrene (2) $(0.57 \mathrm{~g}$, $2.30 \mathrm{mmol})$ and dry DCM $(900 \mathrm{~mL})$ as solvent. The reaction was started by addition of trifluoroacetic acid $(2.09 \mathrm{~mL}, 3.10 \mathrm{~g}, 27.19 \mathrm{mmol})$. After stirring for $1 \mathrm{~h}$, triethylamine $(4.82 \mathrm{~mL}, 3.50 \mathrm{~g}, 34.59 \mathrm{mmol})$ and subsequently DDQ (1.57 g, $6.92 \mathrm{mmol})$ were added to the dark red solution. After stirring for $1 \mathrm{~h}$, the solvent was removed in vacuo and the black residue was purified by column chromatography (hexane:DCM $\left.6: 1 \mathrm{v} / \mathrm{v}, R_{\mathrm{f}}=0.40\right)$. After removal of the solvent, 3 was received as violet crystals. Yield: $0.53 \mathrm{~g}(36 \%)$. ${ }^{1} \mathrm{H}-\mathrm{NMR}\left(600 \mathrm{MHz}, \mathrm{CDCl}_{3}\right): \delta=-2.76(\mathrm{~s}, 2 \mathrm{H}, \mathrm{H}-9$ $+\mathrm{H}-21), 5.38(\mathrm{~d}, J=11.0 \mathrm{~Hz}, 1 \mathrm{H}, \mathrm{H}-50 \mathrm{a}), 5.95$ (d, $J=17.8 \mathrm{~Hz}, 1 \mathrm{H}, \mathrm{H}-50 \mathrm{~b}), 6.97(\mathrm{dd}, J=17.8,11.0 \mathrm{~Hz}$, $1 \mathrm{H}, \mathrm{H}-49), 7.69$ (dd, $J=8.5,7.5 \mathrm{~Hz}, 1 \mathrm{H}, \mathrm{H}-35)$, 7.71-7.78 (m, 9H, H-30 + H-31 + H-32 + H-40+ $\mathrm{H}-41+\mathrm{H}-42+\mathrm{H}-45+\mathrm{H}-46+\mathrm{H}-47), 7.82(\mathrm{~d}, J=$ $8.5 \mathrm{~Hz}, 1 \mathrm{H}, \mathrm{H}-36), 8.10$ (d, $J=7.5 \mathrm{~Hz}, 1 \mathrm{H}, \mathrm{H}-34)$, 8.19-8.23 (m, 6H, H-29 + H-33 + H-39+ H-43+ H$44+\mathrm{H}-48), 8.26$ (s, $1 \mathrm{H}, \mathrm{H}-38), 8.81-8.89(\mathrm{~m}, 8 \mathrm{H}$, $\mathrm{H}-2+\mathrm{H}-3+\mathrm{H}-6+\mathrm{H}-7+\mathrm{H}-12+\mathrm{H}-13+\mathrm{H}-18+\mathrm{H}-$ 19) ppm; ${ }^{13} \mathrm{C}-\mathrm{NMR}\left(150 \mathrm{MHz}, \mathrm{CDCl}_{3}\right): \delta=114.85$ (1C, C-50), 119.86 (1C, C-24), 120.22 (2C, C-17+ C-28), 120.24 (1C, C-11), 125.58 (1C, C-36), 126.72 $(6 \mathrm{C}, \mathrm{C}-30+\mathrm{C}-32+\mathrm{C}-40+\mathrm{C}-42+\mathrm{C}-45+\mathrm{C}-47)$, 126.89 (1C, C-35), 127.76 (3C, C-31 + C-41 + C-46), 131.12 (br., 8C, C-2 + C-3 + C-6 + C-7 + C-12+C-13 $+\mathrm{C}-18+\mathrm{C}-19), 132.51$ (1C, C-38), 134.10 (1C, C-34), 134.60 (6C, C-29+C-33+C-39+ C-43 + C-44 + C-48), 135.95 (1C, C-37), 136.87 (1C, C-49), 142.21 (2C, C-23 + C-26), 142.23 (1C, C-27), 142.49 (1C, C-25) ppm; C-1, C-4, C-8, C-10, C-14, C-16, C-20, C-22 are broad and not detectable; IR (ATR): 3314, 3052, 2954, 2918, 2849, 1809, 1799, 1594, 1574, 1557, 1538, 1471, 1441, 1400, 1394, 1361, 1348, 1311, 1260, 1221, 1191, 1177, 1152, 1092, 1078, 1071, 1056, 1032, 1001, 979, 969, 905, 898, $875,843,815,796,784,756,746,725,706,699,655$, 
$638,620,558 \mathrm{~cm}^{-1}$; EI-MS $(0 \mathrm{eV}): m / z$ [\%] $=641$ (100) $[\mathrm{M}+\mathrm{H}]^{+}, 564(15)[\mathrm{M}-\mathrm{Ph}+\mathrm{H}]^{+} . \mathrm{HRMS}: \mathrm{MH}^{+}$, found: $641.2706 . \mathrm{C}_{46} \mathrm{H}_{33} \mathrm{~N}_{4}$ requires 641.2705.

\subsection{Free radical polymerization $(\mathrm{P} 1, \mathrm{P} 2, \mathrm{P} 3)$}

A glass tube was charged with dry toluene $(5.0 \mathrm{~mL})$, $n$-butyl acrylate $(1.10 \mathrm{~mL}, 1.00 \mathrm{~g}, 7.80 \mathrm{mmol})$, AIBN (11 mg, $0.07 \mathrm{mmol}$ ) and, if appropriate, $1 \mathrm{~mol} \%$ of TPP (48 mg, $0.08 \mathrm{mmol}$ ) or $\mathbf{3}$ (50 mg, $0.08 \mathrm{mmol}$ ), respectively. The sealed tube was shaken for $4 \mathrm{~h}$ at $80^{\circ} \mathrm{C}$ and subsequently the polymerization was stopped by cooling down to room temperature. The polymer solution was poured into cold water $(50 \mathrm{~mL})$ and after phase separation the polymer phase was dissolved in THF $(20 \mathrm{~mL})$ and precipitated in cold water again. The isolated polymer phase was dried in high vacuo. In case of the polymerization in presence of TPP, P2 was dissolved in warm 2-propanol and passed two times through a strongly acidic ion exchange column with Amberlyst 15 (Sigma-Aldrich Chemie $\mathrm{GmbH}$ ) for the removal of TPP.

In case of the copolymerization with $\mathbf{3}, \mathbf{P 3}$ was dissolved in warm 2-propanol and free $\mathbf{3}$ was removed by twofold centrifugation through a Vivaspin 6 (Sartorius AG, Göttingen, Germany) polyethersulfone microcentrifuge filter membrane (MWCO $30 \mathrm{kDa}$ ).

\subsection{Controlled radical copolymerization (P4)}

A glass tube was charged with dry toluene $(5.0 \mathrm{~mL})$, $n$-butyl acrylate $(1.10 \mathrm{~mL}, 1.00 \mathrm{~g}, 7.80 \mathrm{mmol})$, $8 \mathrm{~mol} \%$ 4-vinylpyridine ( $68 \mu \mathrm{L}, 66 \mathrm{mg}, 0.63 \mathrm{mmol})$, AIBN (11 mg, $0.07 \mathrm{mmol}$ ), and the reversible addition-fragmentation chain transfer (RAFT) reagent 2(ethoxycarbonyl)-2-propyldithiobenzoate $(16 \mu \mathrm{L}$, $18 \mathrm{mg}, 0.07 \mathrm{mmol}$ ). The tube was shaken for $4 \mathrm{~h}$ at $80^{\circ} \mathrm{C}$ and subsequently the polymerization was stopped by cooling down to room temperature. The polymer solution was poured into cold water $(50 \mathrm{~mL})$ and after phase separation the polymer phase was
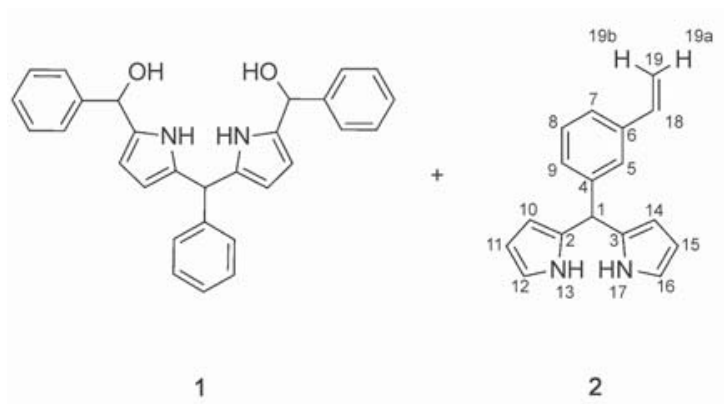

dissolved in THF $(20 \mathrm{~mL})$ and precipitated in cold water again. The isolated polymer phase was dried in high vacuo.

\subsection{Synthesis of $P 3-Z n$}

A round-bottom flask equipped with a magnetic stirring bar was charged with $\mathbf{P 3}$ ( $0.10 \mathrm{~g}, 0.009$ mmeq. porphyrin), $\mathrm{Zn}(\mathrm{OAc})_{2}(50 \mathrm{mg}, 0.27 \mathrm{mmol})$, chloroform $(10 \mathrm{~mL})$ and acetic acid $(40 \mathrm{~mL})$. After stirring for $4 \mathrm{~h}$ at $65^{\circ} \mathrm{C}$, the solvents were removed in vacuo. The residue was dissolved in DCM $(50 \mathrm{~mL})$ and washed with water $(5 \times 10 \mathrm{~mL})$ to remove excess $\mathrm{Zn}(\mathrm{OAc})_{2}$. Subsequently, the organic phase was dried over $\mathrm{Na}_{2} \mathrm{SO}_{4}$ and the solvent removed in vacuo to yield P3-Zn as violet polymer. Yield: $0.10 \mathrm{~g}$ (quantitative).

\section{Results and discussion}

\subsection{Monomer synthesis}

Herein, we applied the general synthetic route given by Lindsey and coworkers for the straightforward synthesis of a mono-vinyl substituted derivative of TPP. According to the general concept, the dipyrromethanedicarbinol 1 has been synthesized following literature procedures $[25,26,30,37]$ in a three step synthesis starting from pyrrole and benzaldehyde, subsequent diacylation of the dipyrromethane with benzoyl chloride and reduction of the diacyl dipyrromethane by $\mathrm{NaBH}_{4}$. Independently, the $m$-vinyl functionalized dipyrromethane $\mathbf{2}$ has been synthesized from commercial 3-vinylbenzaldehyde and pyrrole following general procedures for the synthesis of dipyrromethanes [25, 30, 38]. Finally, $\mathbf{1}$ and $\mathbf{2}$ have been condensed under acidic conditions given in literature and oxidized with DDQ towards 5,10,15-triphenyl-20(3-vinylphenyl)porphyrin (3) (Figure 2). Due to the rational concept of the synthesis, any contamination with potentially crosslinking multi-functionalized porphyrins is absent. With the help of $2 \mathrm{D}-\mathrm{NMR}$
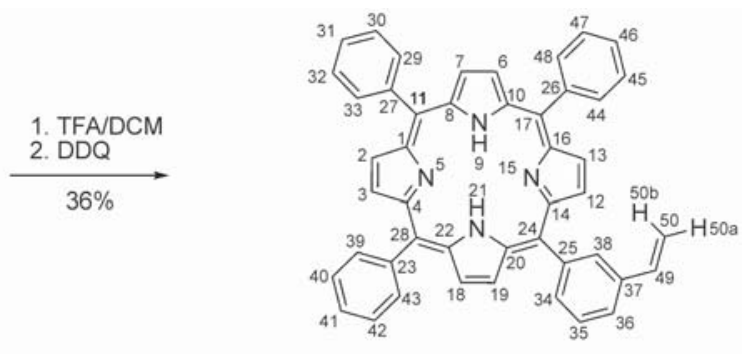

3

Figure 2. Synthesis of 5,10,15-triphenyl-20-(3-vinylphenyl)porphyrin (3) from 3-(bis(1H-pyrrol-2-yl)methyl)styrene (2) and the dipyrromethane-dicarbinol 1. 
techniques, the structure of $\mathbf{3}$ was confirmed unambiguously. The polar $\mathrm{N}-\mathrm{H}$ protons are found at $2.76 \mathrm{ppm}$ in the ${ }^{1} \mathrm{H}-\mathrm{NMR}$ spectra in $\mathrm{CDCl}_{3}$, which is consistent with the ${ }^{1} \mathrm{H}-\mathrm{NMR}$ spectra of TPP.

\subsection{Polymer syntheses}

Due to the limited solubility of porphyrins and their high molecular weight in contrast to typical monomers, the copolymerization of monofunctional porphyrins is not trivial. Copolymers of monoacrylamidophenyl functionalized TPP with styrene [20,39], lauryl methacrylate and vinylimidazole [20] as well as triphenylvinylphenylporphyrin with styrene sulfonate and vinylpyridine [21] have been mentioned. The copolymerization of vinylphenylporphyrins with styrene and methyl methacrylate has been investigated in more detail [40, 41]. An additional hinderance of the copolymerization by the stabilization of the radical at the terminal porphyrin unit by conjugation of the radical with the macrocycle [41] has been revealed. The copolymerization is affected even stronger by the metalloporphyrins [41]. Consequently, here we applied the non-metallized porphyrin as comonomer. Additionally, since the addition of porphyrins limits the polymerization rate, we applied free radical polymerization conditions to achieve a maximal molecular weight and a maximum number of incorporated porphyrins per polymer chain. $n$-Butyl acrylate bearing an unpolar side chain was chosen as comonomer. The polymers achieved are summarized in Table 1.

P1 was prepared by free radical polymerization of $n$-butyl acrylate with AIBN as initiator for comparison in the absence of any porphyrin. To identify the influence of porphyrins on the polymerization, identical conditions have been applied for the synthesis of $\mathbf{P} \mathbf{2}$ in the presence of $1 \mathrm{~mol} \%$ of TPP, which is not in possession of polymerizable functionalities. The molecular weight is lowered in the presence of TPP, but still above $50000 \mathrm{~g} / \mathrm{mol}$. The isolated polymer $\mathbf{P 2}$ revealed an intense violet colour after workup, which indicates significant amounts of TPP to be still present in the polymer. For subsequent investigations of interactions with immobilized porphyrins, obviously all free porphyrins need to be removed. Even after several reprecipitation steps, it was not possible to remove residual TPP from $\mathbf{P 2}$. Still, in the case of $\mathbf{P} 2$, removal was rather straightforward by passing the diluted polymer solution in 2-propanol through a strongly acidic ion exchange column. The heterocyclic nitrogen atoms in porphyrins act as weak bases and may be protonated by strong acids [42] and consequently the free TPP is held back in the ion exchange resin after protonation. The purified polymer still exhibits a slight colouring, which indicates an irreversible binding of few TPP units towards the polymer via radical mechanism. The elemental analysis (nitrogen content $\sim 0.01 \mathrm{wt} \%$ ) proved the absence of any significant amounts of free or incorporated TPP. Repeating the polymerization in presence of $1 \mathrm{~mol} \%$ of 3 led to a comparable molecular weight (P3) which again exhibited an intense colour. For obvious reasons, purification could not be performed via an ion exchange column in this case, as the functionalized polymer would be retained, too. Since reprecipitation was not sufficient to purify $\mathbf{P 3}$, the polymer solution in 2-propanol was purified two times by filtration with a microcentrifuge filter membrane with a molecular cutoff weight around $30000 \mathrm{~g} / \mathrm{mol}$, which holds back solely the high molecular weight polymer P3. The intense colour as well as the elemental analysis proof the incorporation of $\mathbf{3}$ into P3. Referred to $M_{\mathrm{n}}$, an average number of porphyrin ligands per polymer chain can be calculated from the nitrogen content of the elemental analysis to $N \approx 4$, which obviously increases slightly for the higher molecular weight fraction $\left(M_{\mathrm{w}}=75800 \mathrm{~g} / \mathrm{mol}\right)$. This functionality must be accepted to be rather low. In agreement with literature results concerning the copolymerization of styrene with vinylporphyrins [41], the fraction of incorporated porphyrin is in the range of $1-2 \mathrm{~mol} \%$. The limited solubility prohibits a polymerization in

Table 1. Characterization of the polymers used in this work.

\begin{tabular}{|c|c|c|c|c|c|}
\hline Polymer & $\begin{array}{c}M_{\mathrm{n}}{ }^{\mathrm{a}} \\
{[\mathrm{g} / \mathrm{mol}]}\end{array}$ & $M_{\mathrm{w}} / M_{\mathrm{n}}$ & Comonomer & $\begin{array}{c}X \text { (Comonomer }^{\mathrm{b}} \\
{[\mathrm{mol} \%]}\end{array}$ & $N$ Comonomer/chain \\
\hline P1 & 70400 & 1.83 & - & - & - \\
\hline $\mathbf{P 2}$ & 55340 & 1.58 & 'ТPP' & - & - \\
\hline P3 & 48900 & 1.55 & 3 & 1.2 & 4 \\
\hline $\mathbf{P} 4^{\mathrm{c}}$ & 4800 & 1.26 & $4-\mathrm{VP}$ & 15.3 & 6 \\
\hline
\end{tabular}

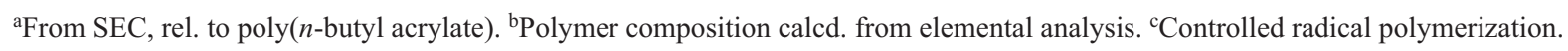


presence of higher amounts of $\mathbf{3}$ in the monomer feed and $\mathbf{P} \mathbf{3}$ represents the achievable upper limit. In contrast to the results reported for the copolymerization of vinylporphyrins with styrene [41], the formation of insoluble polymers during the polymerization in presence of the porphyrin monomer was not observed.

To finalize the first macromolecular binding partner, metal ions need to be inserted into the immobilized porphyrin. Metalloporphyrins with paramagnetic metal ions are known to be rather reactive and although their catalytic activity is of interest in several cases, catalytic oxidation and other catalytic activities are undesired here. Consequently, we decided to choose diamagnetic metal salts for complex formation. The $\mathrm{Sn}(\mathrm{II})\left(\mathrm{d}^{10} \mathrm{~s}^{2}\right)$ metalloporphyrin is known to be unstable and readily decomposes towards the $\mathrm{Sn}(\mathrm{IV})$ species [43], which is in possession of two additional monoanionic axial ligands and consequently inadequate for subsequent axial coordination of pyridine. The $\mathrm{Mg}(\mathrm{II})$ complex $\left(\mathrm{s}^{2} \mathrm{p}^{6}\right)$ is rather reactive and light sensitive [31], too, and consequently $\mathrm{Zn}(\mathrm{II})\left(\mathrm{d}^{10}\right)$ was chosen as central metal. Following a general procedure for the synthesis of metalloporphyrins [31], P3 was treated with a thirty-fold excess of $\mathrm{Zn}(\mathrm{OAc})_{2}$ in $\mathrm{HOAc} / \mathrm{CHCl}_{3}$ and the reaction was monitored by UV/Vis spectroscopy (Figure 3). For comparison, the same reaction was performed with free TPP.

The insertion of $\mathrm{Zn}$ (II) in TPP leads to a significant bathochromic shift of the intense porphyrin Soret $(B)$ band $\left(\mathrm{S}_{0}-\mathrm{S}_{2}\right)$ from 418 to $422 \mathrm{~nm}$ (Figure 3a) which is consistent with literature results in comparable solvents [44]. The reaction of $\mathbf{P 3}$ with $\mathrm{Zn}(\mathrm{OAc})_{2}$ leads to a significant bathochromic shift by $9 \mathrm{~nm}$ of the Soret band, too (P3: $\left.\lambda_{B}=420 \mathrm{~nm}, \mathbf{P 3 - Z n} \lambda_{\mathrm{B}}=429 \mathrm{~nm}\right)$.

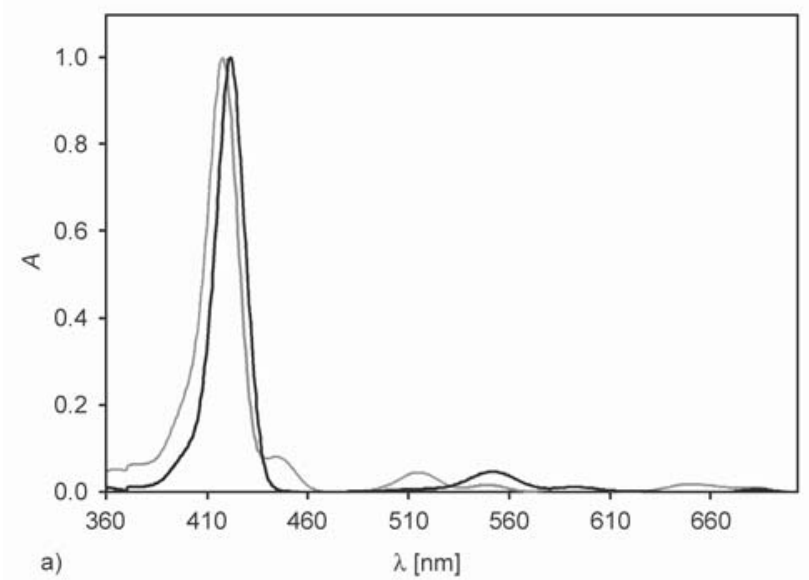

The UV/Vis spectra reveal a complete shift of the Soret band proving the complete conversion of the immobilized porphyrin to the $\mathrm{Zn}$ (II) complex (Figure $3 b$ ).

As molecular counterpart to $\mathbf{P 3 - Z n}$, a copolymer of 4-vinylpyridine (4-VP) with $n$-butyl acrylate was synthesized. To easily identify both polymers in a polymer mixture, the molecular weight of the second polymer was limited via controlled radical polymerization conditions. The copolymerization of 4-VP with $n$-butyl acrylate is generally well investigated [45] and according to the copolymerization parameters, preferred incorporation of 4-VP is expected. 2(Ethoxycarbonyl)-2-propyldithiobenzoate (ECPDB) was chosen as chain transfer agent (CTA) for the radical copolymerization controlled by reversible addition-fragmentation chain transfer (RAFT). ECPDB is known as CTA for acrylates, and dithiobenzoates have successfully been applied for the controlled radical homopolymerization of 4-VP [46]. After a rather short polymerization time of $4 \mathrm{~h}, \mathbf{P} 4$ with a molecular mass of $M_{\mathrm{n}}=4800 \mathrm{~g} / \mathrm{mol}$ (see Table 1) was isolated. The preferred copolymerization of 4-VP leads to a fraction of $15 \mathrm{~mol} \%$ of $4-\mathrm{VP}$ in $\mathbf{P 4}$. Consequently, the number of binding sites per polymer chain is calculated to $N \approx 6$. Overall, the polymer P3$\mathbf{Z n}$ and its counterpart $\mathbf{P 4}$ differ in molecular weight by a factor of 10 , but provide roughly the same number of binding sites per polymer chain.

\subsection{Interaction}

The axial binding of pyridine towards metalloporphyrins is generally well known $[47,48]$ and has been used for the synthesis of supramolecular crystal structures [49]. The binding of one pyridine ligand to

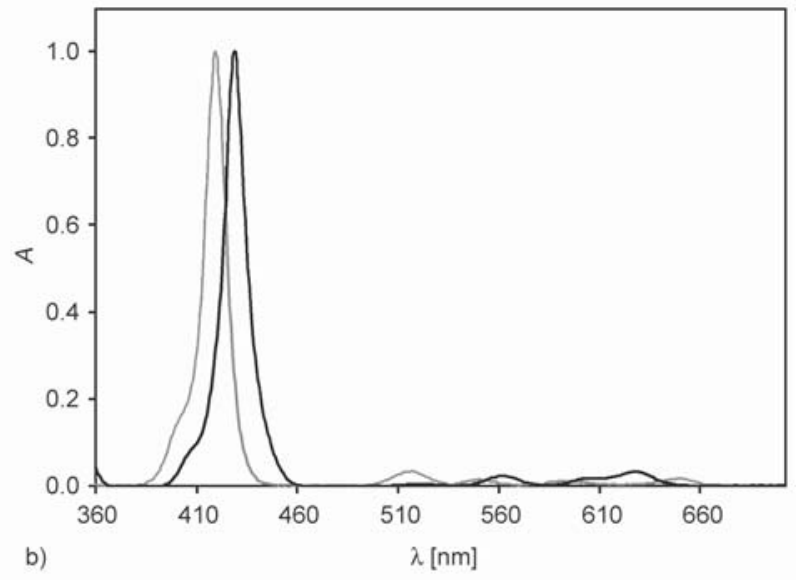

Figure 3. UV/Vis spectra of (a) TPP (grey) and TPP-Zn (black) and (b) P3 (grey) and P3-Zn (black) measured in chloroform. 

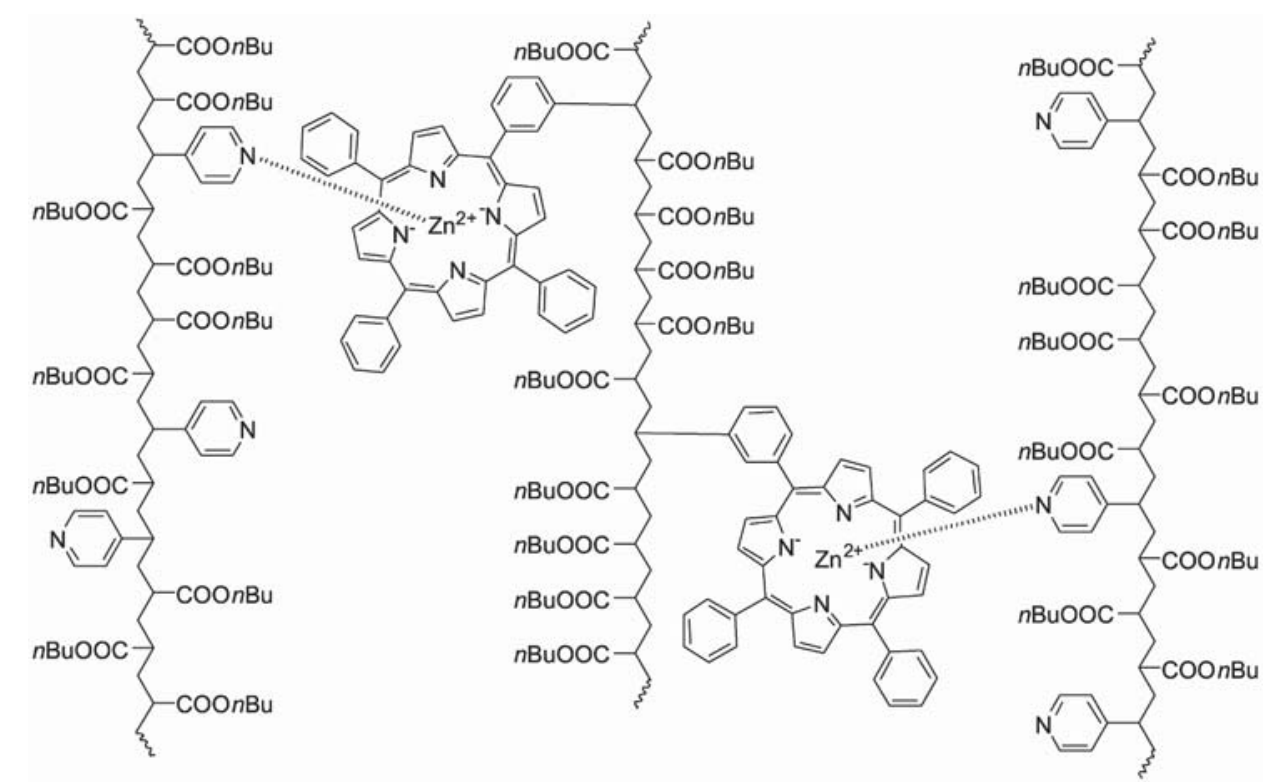

Figure 4. Supramolecular network formed by coordination of poly( $n$-butyl acrylate-co-4-vinylpyridine) to poly( $n$-butyl acrylate-co-5,10,15-triphenyl-20-(3-vinylphenyl)porphyrin zinc(II)).

TPP-Zn is rather strong [47] while coordination of a second pyridine unit does not take place (Figure 4). To investigate the selective binding of $\mathbf{P} 4$ towards P3-Zn via the coordination of the immobilized 4-VP towards the immobilized zinc(II) porphyrin here, the two polymers were mixed and the mixing monitored by diffusion ordered NMR spectroscopy (DOSY). In DOSY NMR spectra, 1D-NMR spectra (usually ${ }^{1} \mathrm{H}-\mathrm{NMR}$ ) are separated by the diffusion coefficient of each component.

The most intense ${ }^{1} \mathrm{H}-\mathrm{NMR}$ signals corresponding to the $n$-butyl side chain $(\delta=4.04,1.60,1.38$,
$0.94 \mathrm{ppm}$ ) were used for the evaluation of the DOSY data for both copolymers. The diffusion coefficient of $\mathbf{P 4}$ in $\mathrm{CDCl}_{3}$ (Figure 5b) was estimated to $D=$ $2.7 \cdot 10^{-10} \mathrm{~m}^{2} \cdot \mathrm{s}^{-1}$ which correlates with a hydrodynamic radius of $R_{\mathrm{h}}=1.5 \mathrm{~nm}$ according to the StokesEinstein equation. For a rough comparison, recalculating this hydrodynamic radius to a molecular weight of polystyrene (PS) in a good solvent [50] leads to $M \approx 5000 \mathrm{~g} / \mathrm{mol}$ which matches well with the molecular weight determined by SEC. The diffusion coefficient of P3-Zn is estimated to $D=1.1 \cdot 10^{-10} \mathrm{~m}^{2} \cdot \mathrm{s}^{-1}$ (Figure 5a) which correlates with $R_{\mathrm{h}}=3.8 \mathrm{~nm}$ and is

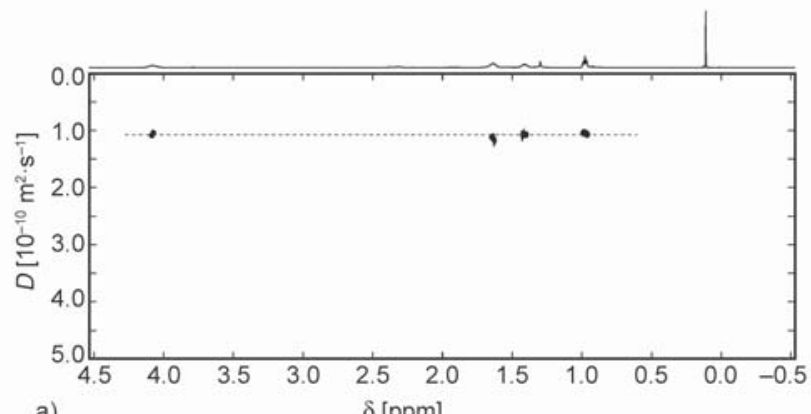

a)
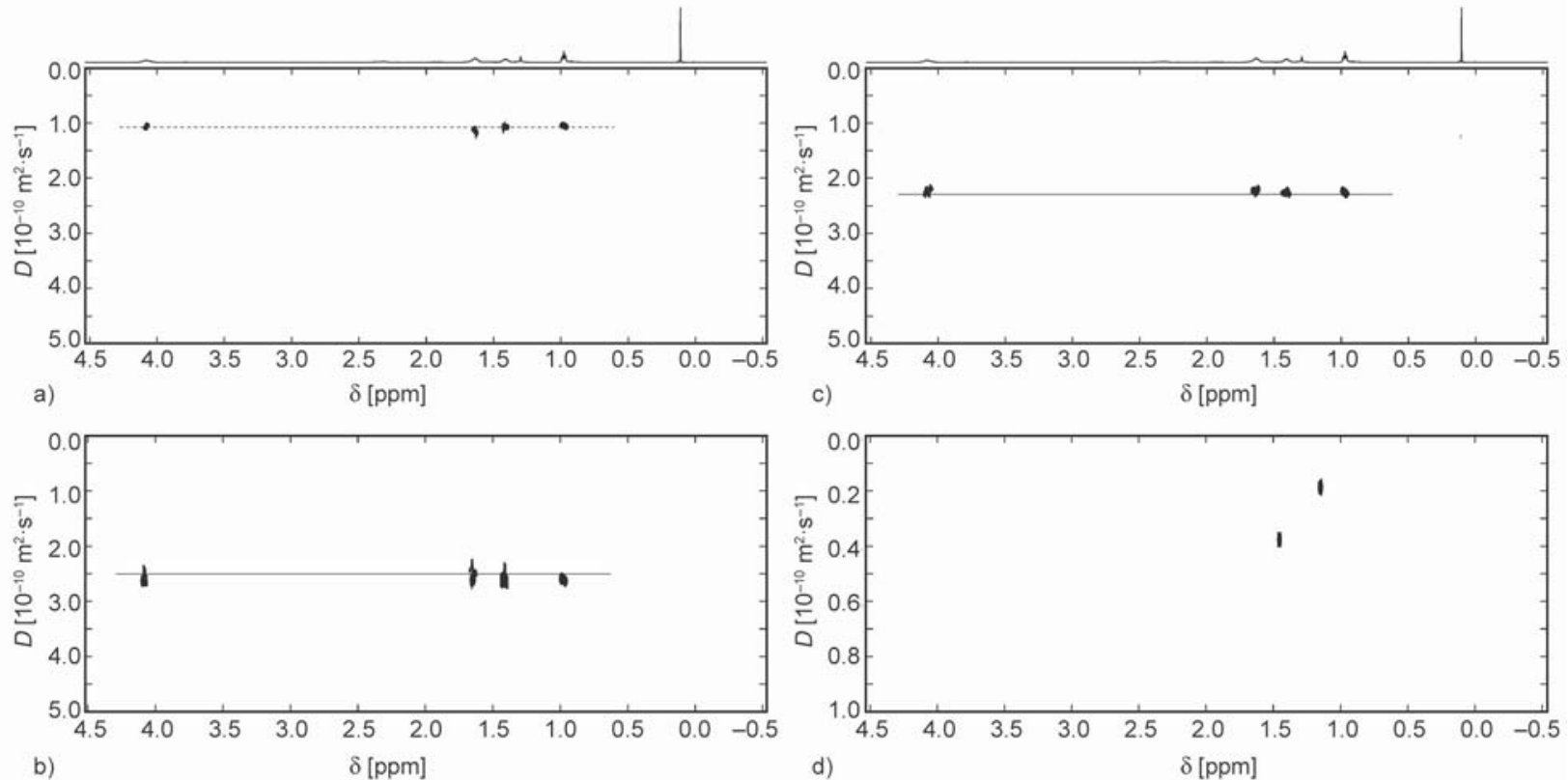

Figure 5. DOSY NMR spectra of (a) P3-Zn, (b) P4, (c) the 1:1 (w/w) mixture of P3-Zn and P4 and (d) the high molecular weight fraction of the mixture. All NMR spectra measured in $\mathrm{CDCl}_{3}$ (lines are guide to the eye). 
recalculated to $M \approx 30000 \mathrm{~g} / \mathrm{mol}$ (rel. PS) which does not exactly match with the SEC, but is in acceptable agreement keeping in mind the assumptions made for this rough estimation. In the mixture of $\mathbf{P 4}$ and $\mathbf{P 3 - Z n}$, clearly solely the polymer $\mathbf{P} 4$ can be identified (Figure 5c). Since the signal intensity in ${ }^{1} \mathrm{H}-\mathrm{NMR}$ spectroscopy is proportional to the fraction of chemically identical protons, the mixture of $\mathbf{P 3 - Z n}$ and $\mathbf{P 4}$ in a mass-ratio of 1:1 should reveal both polymers with comparable signal intensity keeping in mind both copolymers to be based on $n$-butyl acrylate. Consequently, $\mathbf{P 3 - Z n}$ has been completely precipitated in the polymer mixture and only residual $\mathbf{P 4}$ is observed. This result is well understandable assuming the networking formation visualized in Figure 4. Coordination of the immobilized pyridine towards the immobilized TPP-Zn connects several polymer chains of P3-Zn via $\mathbf{P 4}$ and the resulting large polymer networks are not identified by DOSY any longer. Although the number of binding sites per polymer chain of $\mathbf{P 3 - Z n}$ and $\mathbf{P 4}$ is roughly the same, the lower molecular weight polymer $\mathbf{P 4}$ leads to complete binding of P3-Zn with a small amount of P4, while free $\mathbf{P} 4$ remains in solution. The mixing experiment was repeated with varying ratios of $\mathbf{P 3 - Z n}$ and $\mathbf{P 4}$ and in all cases only residual $\mathbf{P 4}$ was visible. Since the signal intensity of the NMR spectra is naturally connected to the amount of polymer present, the amount of $\mathbf{P} 4$ cannot be lowered infinitely. During some of the mixing experiments, we were able to identify a very slow diffusing species (Figure 5d) which correlates roughly to a molecular weight around $500000 \mathrm{~g} / \mathrm{mol}$ and may belong to fragments of the supramolecular network.

Additionally, the DOSY experiment was repeated at increasing temperatures. Surprisingly, up to $60^{\circ} \mathrm{C}$ no indication for the formation of two isolated polymers was notified. This indicates a very strong binding of the two polymers (see below.) Temperatures above $60^{\circ} \mathrm{C}$ could not be applied due to increasing convection inside the NMR tube.

To cross-check these results, the supramolecular binding between $\mathbf{P 3 - Z n}$ and $\mathbf{P 4}$ was investigated by size exclusion chromatography (SEC). The strongly differing molecular weights, which only slightly overlap, easily allow identifying both polymers. In the 1:1 mixture of P3-Zn and P4, SEC proved the nearly complete absence of residual $\mathbf{P 3 - Z n}$, which has been precipitated and filtered off by the prefilter column

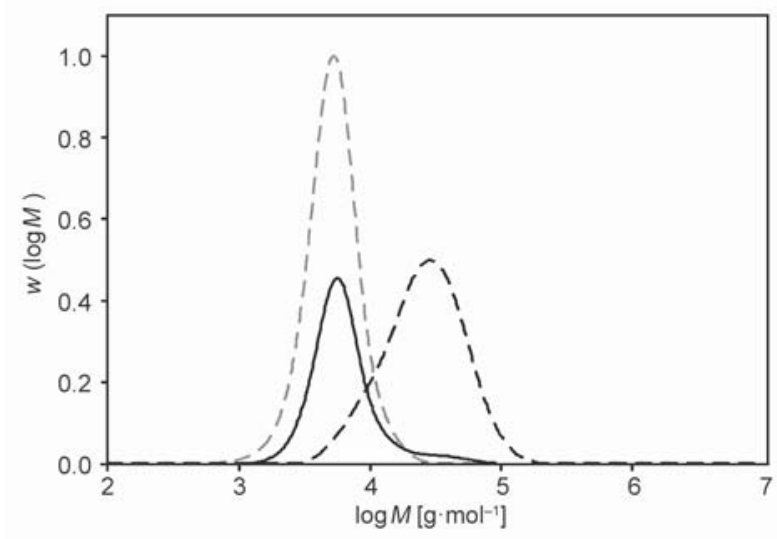

Figure 6. Molecular weight distribution analyzed by SEC of P4 (dashed gray line), P3-Zn (dashed black line), and the 1:1 (w/w) mixture of P3-Zn and $\mathbf{P 4}$ (black line).

of the SEC, while in good agreement with the DOSY experiment free $\mathbf{P 4}$ is still detected (Figure 6).

It should be noted, that the copolymer composition obviously has an effect on the signal intensity of the refractive index detector, but both copolymers are based on the same main comonomer ( $n$-butyl acrylate) and the nearly complete removal of the high molecular weight signal can only be explained by the removal of P3-Zn. The very small residual amount of P3-Zn notified in the SEC experiment has not been observed in the DOSY measurements, which probably is caused by the higher detection limit of the NMR spectroscopy. An explanation for this residual amount of free P3-Zn may be given by the still rather low functionality of an average of four porphyrin moieties per polymer chain, which statistically has to lead to a small fraction of unfunctionalized polymer chains, too.

The coordination of $\mathrm{N}$-donors such as triethylamine and pyridine towards TPP-Zn has been investigated in detail via UV/Vis absorption spectroscopy in literature $[47,51,52]$. In chloroform, coordination of $\mathrm{N}$-donors towards the zinc(II) centre of porphyrins leads only to a very small bathochromic shift around $1 \mathrm{~nm}$ [51]. Consequently, complex formation was investigated in dichloromethane. For comparison, TPP-Zn has been treated with pyridine under the same conditions, too. The UV/Vis spectra reveal a bathochromic shift of the Soret band by $9 \mathrm{~nm}$ upon addition of pyridine to the pink solution of TPP-Zn and additionally a bathochromic shift of the Q-band at 548 by $12 \mathrm{~nm}$ upon coordination of pyridine (Figure 7). The addition of 10 eq. of pyridine leads to a 


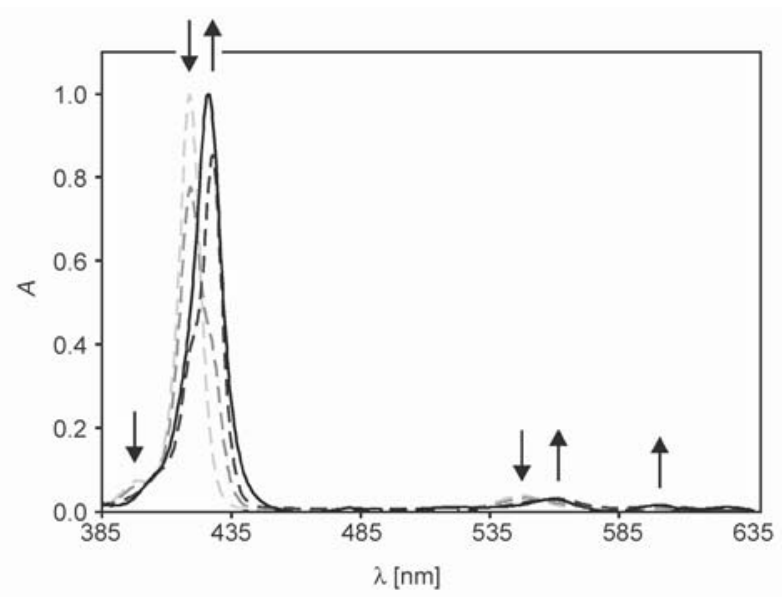

Figure 7. UV/Vis spectra of TPP-Zn (light-grey dashed), after addition of 10 eq. pyridine (grey, dashed), after addition of 100 eq. pyridine (dark grey, dashed) and the 1:1 (w/w) mixture of P3-Zn and P4 (black line) measured in dichloromethane.

small decrease of the Soret band at $419 \mathrm{~nm}$, while the new Soret band at $428 \mathrm{~nm}$ is recognized as a shoulder. Addition of 100 eq. of pyridine leads to a pale yellow solution with an intense Soret band at $428 \mathrm{~nm}$ while residual free TPP-Zn is indicated as a weak shoulder at $419 \mathrm{~nm}$.

For the pale yellow 1:1 (w/w) mixture of P3-Zn and $\mathbf{P 4}$, the Soret band at $426 \mathrm{~nm}$ as well as the complete Q-band region indicate perfect agreement with the pyridine coordinated complex, while any residual signals of the uncoordinated zinc(II) complex are barely visible. Keeping in mind the $1: 1(\mathrm{w} / \mathrm{w})$ mixture to contain a molar ratio of immobilized zinc(II)porphyrin:pyridine of roughly 1:10, a significantly stronger binding of the immobilized species in comparison to the molecular counterparts is observed.

This strong coordinative binding is in agreement with the results of the DOSY measurements, which did not reveal any indication for free P3-Zn up to $60^{\circ} \mathrm{C}$ and consequently no indication for the breaking of the coordinative zinc(II)-pyridine bond as discussed above. The binding of pyridine towards the molecular complex TPP-Zn has been investigated in literature and the equilibrium constant was found to be strongly temperature dependent [47]. To further investigate the binding behaviour, the interaction of pyridine with TPP-Zn was analyzed by density functional theory (DFT) calculations. The calculated structure of the complex revealed a distortion of the zinc(II) ion by $d=0.330 \AA$ (TPP-Zn: $0.000 \AA$ ) out of the porphyrin plane upon coordination of pyridine (Figure 8). This is in good agreement with the distortion

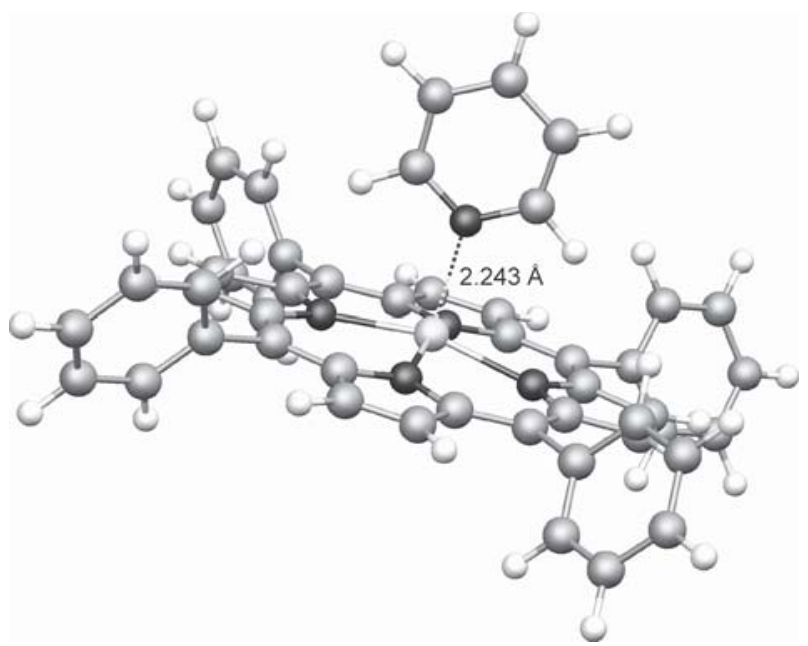

Figure 8. Calculated structure of the TPP-Zn pyridine complex.

of the zinc(II) ion revealed by the crystal structure of comparable compounds such as the zinc tetraphenylbacteriochlorin pyridine complex $(d=0.320 \AA)$ [53] and the zinc tetraphenylisobacteriochlorin pyridine complex $(d=0.323 \AA)$ [54]. Additionally, the calculated pyridine-Zn(II) bond length of $d_{\mathrm{Py}-\mathrm{Zn}}=$ $2.243 \AA$ is in good agreement with the crystal structures $\left(d_{\mathrm{Py}-\mathrm{Zn}}=2.164 \AA\right.$ and $d_{\mathrm{Py}-\mathrm{Zn}}=2.155 \AA$, respectively).

The calculated free Gibbs energy of the coordination of pyridine towards TPP-Zn was calculated to $\Delta_{\mathrm{r}} G_{298}=$ $-14 \mathrm{~kJ} / \mathrm{mol}$. This is in good agreement to data determined in literature $\left(\Delta_{\mathrm{r}} G_{303}=-21 \mathrm{~kJ} / \mathrm{mol}\right)$ [47] and can not explain the strong binding even at elevated temperatures. On the other hand, the pure reaction energy neglecting the entropic part was calculated to $\Delta_{\mathrm{r}} E=-62 \mathrm{~kJ} / \mathrm{mol}$. Consequently, and not surprisingly, the binding strength is strongly affected by the entropy. For the multifunctional polymers P3-Zn and $\mathbf{P 4}$, a similar situation as in chelate complexes is present. After the first coordination, the influence of the entropy on the coordination of subsequent pyridine moieties towards the other incorporated zinc porphyrins becomes more and more negligible and consequently a strong binding is revealed. The binding of two axial pyridine moieties towards one TPP-Zn complex is unfavoured, as mentioned above.

\section{Conclusions}

Following a rational approach to monofunctionalized tetraphenylporphyrins given in literature, the monomer 5,10,15-triphenyl-20-(3-vinylphenyl)porphyrin (3) was synthesized in a 5-step synthesis without contamination of multifunctional and potentially 
crosslinking porphyrins. The free radical copolymerization with $n$-butyl acrylate led to an intensively coloured polymer with a molecular weight around $50000 \mathrm{~g} / \mathrm{mol}$. The incorporation of the porphyrin into $\operatorname{poly}(n$-butyl acrylate) was found to take place up to a fraction of $1 \mathrm{~mol} \%$, corresponding to 4 porphyrin units per polymer chain. Subsequently, the immobilized porphyrin was readily metallized with zinc(II) towards the corresponding metalloporphyrin.

By controlled radical polymerization via the RAFT process, poly( $n$-butyl acrylate-co-4-vinylpyridine) with a molecular weight around $5000 \mathrm{~g} / \mathrm{mol}$ and a number of 6 pyridine moieties per polymer chain was obtained. Finally, the two polymers were combined to investigate their attractive interaction via the coordination of pyridine towards the zinc(II) centres. With the help of DOSY NMR spectroscopy and SEC, the complete precipitation of the porphyrin functionalized polymer was observed, confirming the expected network formation. Overall, we report on the first evidence for a strong velcro-like binding between a porphyrin-functionalized polymer with a pyridine-functionalized polymer. The system based on immobilized N-donors and metalloporphyrins presented here may easily be adapted to control the desired binding strength by the choice of the metal ion and N-donor. Current work focuses on surface functionalization via surface-initiated polymerization with both polymers as the next step towards molecular velcro, and, owed to the limited incorporation of the porphyrin monomer $\mathbf{3}$, the direct surface functionalization with porphyrins.

\section{Acknowledgements}

M. Sievers gratefully acknowledges funding by the Deutsche Forschungsgemeinschaft (DFG) (project HU 1888/3-1). We thank Martina Heinz and Werner Bischof from the Institute of Technical Chemistry for SEC measurements and elemental analyses.

\section{References}

[1] Giraud C., Bernard C., Ruer S., de Benztmann S.: Biological 'glue' and 'velcro': Molecular tools for adhesion and biofilm formation in the hairy and gluey bug Pseudomonas aeruginosa. Environmental Microbiology Reports, 2, 343-358 (2010). https://doi.org/10.1111/j.1758-2229.2009.00070.x

[2] Zhang S.: Emerging biological materials through molecular self-assembly. Biotechnology Advances, 20, 321-339 (2002).

https://doi.org/10.1016/S0734-9750(02)00026-5
[3] Gutsmann T., Hassenkam T., Cutroni J. A., Hansma P. K.: Sacrificial bonds in polymer brushes from rat tail tendon functioning as nanoscale velcro. Biophysical Journal, 89, 536-542 (2005) https://doi.org/10.1529/biophysj.104.056747

[4] Ye Q., Zhou F., Liu W.: Bioinspired catecholic chemistry for surface modification. Chemical Society Reviews, 40, 4244-4258 (2011).

https://doi.org/10.1039/c1cs15026j

[5] Westwood G., Horton T. N., Wilker J. J.: Simplified polymer mimics of cross-linking adhesive proteins. Macromolecules, 40, 3960-3964 (2007).

https://doi.org/10.1021/ma0703002

[6] Gersappe D., Irvine D., Balazs A. C., Liu Y., Sokolov J., Rafailovich M., Schwarz S., Peiffer D. G.: The use of graft copolymers to bind immiscible blends. Science, 265, 1072-1074 (1994).

https://doi.org/10.1126/science.265.5175.1072

[7] O'Connor K. P., McLeish T. C. B.: 'Molecular velcro': Dynamics of a constrained chain into an elastomer network. Macromolecules, 26, 7322-7325 (1993).

https://doi.org/10.1021/ma00078a031

[8] Harada A., Kobayashi R., Takashima Y., Hashidzume A., Yamaguchi H.: Macroscopic self-assembly through molecular recognition. Nature Chemistry, 3, 34-37 (2011).

https://doi.org/10.1038/nchem.893

[9] Voskuhl J., Wendeln C., Versluis F., Fritz E-C., Roling O., Zope H., Schulz C., Rinnen S., Arlinghaus H. F., Ravoo B. J., Kros A.: Immobilization of liposomes and vesicles on patterned surfaces by a peptide coiled-coil binding motif. Angewandte Chemie International Edition, 51, 12616-12620 (2012).

https://doi.org/10.1002/anie.201204836

[10] Ahn Y., Jang Y., Selvapalam N., Yun G., Kim K.: Supramolecular velcro for reversible underwater adhesion. Angewandte Chemie International Edition, 52, 31403144 (2013).

https://doi.org/10.1002/anie.201209382

[11] Guo J., Yuan C., Guo M., Wang L., Yan F.: Flexible and voltage-switchable polymer velcro constructed using host-guest recognition between poly(ionic liquid) strips. Chemical Science, 5, 3261-3266 (2014).

https://doi.org/10.1039/c4sc00864b

[12] Lederle F., Hübner E. G.: Radical polymerization of styrene in presence of poly(2,2,6,6-tetramethylpiperidine- $N$-oxyl-4-yl methacrylate) - formation of polymer brushes. Polymer, 111, 258-264 (2017).

https://doi.org/10.1016/j.polymer.2017.01.053

[13] Freytag K., Säfken S., Wolter K., Namyslo J. C., Hübner E. G.: Hybrid single-chain nanoparticles via the metal induced crosslinking of $\mathrm{N}$-donor functionalized polymer chains. Polymer Chemistry, 8, 7546-7558 (2017). https://doi.org/10.1039/C7PY01487B 
[14] Ribó J. M., Sesé M. L., Trull F. R.: Insoluble polymersupported porphyrins as photosensitizers. in 'Photosensitisation: Molecular, cellular and medical aspects' (eds.: Moreno G., Pottier R. H., Truscott T. G.) Springer, Berlin, Vol 15, 361-363 (1988).

https://doi.org/10.1007/978-3-642-73151-8 51

[15] Ribo J. M., Sese M. L., Trull F. R.: Polymer-bound pyrrole compounds. IV. Polystyrene-bound porphyrins as ${ }^{1} \mathrm{O}_{2}$ photosensitizers. Bilirubin photooxidation as a probe for their efficiencies. Reactive Polymers, 10, 239-258 (1989).

https://doi.org/10.1016/0923-1137(89)90031-6

[16] Eichhorn H., Sturm M., Wöhrle D.: Polymer-bound porphyrins and their precursors, 11 . Syntheses and polymerization of methacryloyloxy and 2,4-hexadienoyloxy derivatives of porphyrins and phthalocyanines. Macromolecular Chemistry and Physics, 196, 115-131 (1995). https://doi.org/10.1002/macp.1995.021960107

[17] Wöhrle D., Paliuras M., Okura I.: Polymer-bound porphyrins and their precursors, 10. Syntheses and photoredox properties of water-soluble polymers with covalently bonded zinc tetraphenylporphyrin. Macromolecular Chemistry and Physics, 192, 819-832 (1991) https://doi.org/10.1002/macp.1991.021920407

[18] Adler A. D., Longo F. R., Finarelli J. D., Goldmacher J., Assour J., Korsakoff L.: A simplified synthesis for meso-tetraphenylporphine. The Journal of Organic Chemistry, 32, 476 (1967). https://doi.org/10.1021/jo01288a053

[19] Adler A. D., Longo F. R., Shergalis W.: Mechanistic investigations of porphyrin syntheses. I. Preliminary studies on $m s$-tetraphenylporphin. Journal of the American Chemical Society, 86, 3145-3149 (1964).

https://doi.org/10.1021/ja01069a035

[20] Hasegawa E., Nemoto J-I., Kanayama T., Tsuchida E.: Syntheses and properties of vinyl monomers containing a meso-tetraphenylporphin ring and their copolymers. European Polymer Journal, 14, 123-127 (1978). https://doi.org/10.1016/0014-3057(78)90076-9

[21] Sumi K., Kimura M., Nakamura I.: Syntheses of homopolymer and water-soluble polymers containing tetraphenylporphinatomanganese(III) complex, and ligand substitution reaction for anionic ligand. Journal of Polymer Science Part A: Polymer Chemistry, 32, 1243-1254 (1994). https://doi.org/10.1002/pola.1994.080320705

[22] Lemon C. M., Karnas E., Bawendi M. G., Nocera D. G.: Two-photon oxygen sensing with quantum dot-porphyrin conjugates. Inorganic Chemistry, 52, 10394 10406 (2013). https://doi.org/10.1021/ic4011168

[23] Wennerström O., Ericsson H., Raston I., Svensson S., Pimlott W.: meso-tetra(meso-tetraphenylporphyrinyl) porphyrin, a macrocycle with five covalently linked porphyrin units. Tetrahedron Letters, 30, 1129-1132 (1989). https://doi.org/10.1016/S0040-4039(01)80378-6
[24] Ema T., Jittani M., Furuie K., Utaka M., Sakai T.: 5-[4(1-hydroxyethyl)phenyl]-10,15,20-triphenylporphyrin as a probe of the transition-state conformation in hydrolase-catalyzed enantioselective transesterifications. The Journal of Organic Chemistry, 67, 2144-2151 (2002). https://doi.org/10.1021/jo0109063

[25] Rao P. D., Dhanalekshmi S., Littler B. J., Lindsey J. S.: Rational syntheses of porphyrins bearing up to four different meso substituents. The Journal of Organic Chemistry, 65, 7323-7344 (2000).

https://doi.org/10.1021/jo000882k

[26] Gryko D., Lindsey J. S.: Rational synthesis of mesosubstituted porphyrins bearing one nitrogen heterocyclic group. The Journal of Organic Chemitry, 65, 2249-2252 (2000).

https://doi.org/10.1021/jo9918100

[27] Tanaka K., Pescitelli G., Nakanishi K., Berova N.: Fluorescence detected exciton coupled circular dichroism: Development of new fluorescent reporter groups for structural studies. Monatshefte für Chemie, 136, 367395 (2005).

https://doi.org/10.1007/s00706-004-0276-5

[28] Tomizaki K-Y., Lysenko A. B., Taniguchi M., Lindsey J. S.: Synthesis of phenylethyne-linked porphyrin dyads. Tetrahedron, 60, 2011-2023 (2004).

https://doi.org/10.1016/j.tet.2004.01.003

[29] Hondros C. J., Aravindu K., Diers J. R., Holten D., Lindsey J. S., Bocian D. F.: Effects of linker torsional constraints on the rate of ground-state hole transfer in porphyrin dyads. Inorganic Chemistry, 51, 1107611086 (2012). https://doi.org/10.1021/ic301613k

[30] Littler B. J., Miller M. A., Hung C-H., Wagner R. W., O’Shea D. F., Boyle P. D., Lindsey J. S.: Refined synthesis of 5-substituted dipyrromethanes. The Journal of Organic Chemistry, 64, 1391-1396 (1999). https://doi.org/10.1021/jo982015+

[31] Rothemund P., Menotti A. R.: Porphyrin studies. V. ${ }^{1}$ The metal complex salts of $\alpha, \beta, \gamma, \delta$-tetraphenylporphine. Journal of the American Chemical Society, 70, 18081812 (1948). https://doi.org/10.1021/ja01185a047

[32] Beuermann S., Paquet D. A., McMinn J. H., Hutchinson R. A.: Determination of free-radical propagation rate coefficients of butyl, 2-ethylhexyl, and dodecyl acrylates by pulsed-laser polymerization. Macromolecules, 29, 4206-4215 (1996). https://doi.org/10.1021/ma960081c

[33] Pelta M. D., Morris G. A., Stchedroff M. J., Hammond S. J.: A one-shot sequence for high-resolution diffusionordered spectroscopy. Magnetic Resonance in Chemistry, 40, S147-S152 (2002). https://doi.org/10.1002/mrc. 1107

[34] Nilsson M.: The DOSY toolbox: A new tool for processing PFG NMR diffusion data. Journal of Magnetic Resonance, 200, 296-302 (2009). https://doi.org/10.1016/j.jmr.2009.07.022 
[35] Holz M., Mao X-A., Seiferling D., Sacco A.: Experimental study of dynamic isotope effects in molecular liquids: Detection of translation rotation coupling. The Journal of Chemical Physics, 104, 669-679 (1996). https://doi.org/10.1063/1.470863

[36] Bochevarov A. D., Harder E., Hughes T. F., Greenwood J. R., Braden D. A., Philipp D. M., Rinaldo D., Halls M. D., Zhang J., Friesner R. A.: Jaguar: A high-performance quantum chemistry software program with strengths in life and materials sciences. International Journal of Quantum Chemistry, 113, 2110-2142 (2013). https://doi.org/10.1002/qua.24481

[37] Geier G. R., Chick J. F. B., Callinan J. B., Reid C. G., Auguscinski W. P.: A survey of acid catalysis and oxidation conditions in the two-step, one-flask synthesis of meso-substituted corroles via dipyrromethanedicarbinols and pyrrole. The Journal of Organic Chemistry, 69, 4159-4169 (2004).

https://doi.org/10.1021/jo0496493

[38] Biaggi C., Benaglia M., Raimondi L., Cozzi F.: Organocatalytic synthesis of dipyrromethanes by the addition of $N$-methylpyrrole to aldehydes. Tetrahedron, 62, 12375-12379 (2006). https://doi.org/10.1016/j.tet.2006.09.104

[39] Tsuchida E., Hasegawa E., Kanayama T.: Oxygenation of polymer-covalently bonded metalloporphyrins. Macromolecules, 11, 947-955 (1978).

https://doi.org/10.1021/ma60065a021

[40] Kitsenko N. A., Ishkov Y. V., Voloshanovskii I. S., Aliev Z. G., Pomogailo A. D.: Preparation and reactivity of metal-containing monomers 44. Synthesis and structure of vinylporphyrins and their metal complexes. Russian Chemical Bulletin, 44, 1758-1763 (1995).

https://doi.org/10.1007/BF01151307

[41] Pomogailo A. D., Bravaya N. M., Razumov V. F., Voloshanovskii I. S., Kitsenko N. A., Berezovskii V. V., Kuzaev A. I., Ivanchenko A. G.: Preparation and reactivity of metal-containing monomers 46 . Copolymerization of vinylporphyrin metal complexes and the structure of the products. Russian Chemical Bulletin, 45, 2773-2780 (1996).

https://doi.org/10.1007/BF01430641

[42] Su B., Li F., Partovi-Nia R., Gros C., Barbe J-M., Samec Z., Girault H. H.: Evidence of tetraphenylporphyrin monoacids by ion-transfer voltammetry at polarized liquid|liquid interfaces. Chemical Communications, 2008, 5037-5038 (2008).

https://doi.org/10.1039/b811886h

[43] Barbe J. M., Ratti C., Richard P., Lecomte C., Gerardin R., Guilard R.: Tin(II) porphyrins: Synthesis and spectroscopic properties of a series of divalent tin porphyrins. X-ray crystal structure of $(2,3,7,8,12,13,17,18$ octaethylprophinato)tin(II). Inorganic Chemistry, 29, 4126-4130 (1990).

https://doi.org/10.1021/ic00345a043

[44] Edwards L., Dolphin D. H., Gouterman M., Adler A. D.: Porphyrins XVII. Vapor absorption spectra and redox reactions: Tetraphenylporphins and porphin. Journal of Molecular Spectroscopy, 38, 16-32 (1971). https://doi.org/10.1016/0022-2852(71)90090-7
[45] Funt B. L., Ogryzlo E. A.: Copolymerization of butyl acrylate and vinylpyridine. Journal of Polymer Science Part A: Polymer Chemistry, 25, 279-284 (1957). https://doi.org/10.1002/pol.1957.1202511003

[46] Convertine A. J., Sumerlin B. S., Thomas D. B., Lowe A. B., McCormick C. L.: Synthesis of block copolymers of 2- and 4-vinylpyridine by RAFT polymerization. Macromolecules, 36, 4679-4681 (2003). https://doi.org/10.1021/ma0343611

[47] Miller J. R., Dorough G. D.: Pyridinate complexes of some metallo-derivatives of tetraphenylporphine and tetraphenylchlorin. Journal of the American Chemical Society, 74, 3977-3981 (1952). https://doi.org/10.1021/ja01136a003

[48] Collins D. M., Hoard J. L.: Crystal structure and molecular stereochemistry of $\alpha, \beta, \gamma, \delta$-tetra(4-pyridyl)porphinatomonopyridinezinc(II). Appraisal of bond strain in the porphine skeleton. Journal of the American Chemical Society, 92, 3761-3771 (1970).

https://doi.org/10.1021/ja00715a038

[49] Kumar D. K., Das A., Dastidar P.: Metalloporphyrinbased inclusion materials: Exploiting ligating topologies and hydrogen-bonding backbones in generating new supramolecular architectures. Inorganic Chemistry, 46, 7351-7361 (2007). https://doi.org/10.1021/ic0702163

[50] Fetters L. J., Hadjichristidis N., Lindner J. S., Mays J. W.: Molecular weight dependence of hydrodynamic and thermodynamic properties for well-defined linear polymers in solution. Journal of Physical and Chemical Reference Data, 23, 619-640 (1994). https://doi.org/10.1063/1.555949

[51] Heier P., Förster C., Schollmeyer D., Boscher N., Choquet P., Heinze K.: $\alpha \alpha$ - and $\alpha \beta$-zinc-meso- $\mathrm{A}_{2} \mathrm{~B}_{2}$-tetraarylporphyrins with large optical responses to triethylamine. Dalton Transactions, 42, 906-917 (2013). https://doi.org/10.1039/c2dt31943h

[52] Harada K., Fujitsuka M., Sugimoto A., Majima T.: Electron transfer from the $S_{1}$ and $S_{2}$ states of pentacoordinated tetrapyrrole macrocycles to pyromellitic diimide as an axial ligand. The Journal of Physical Chemistry A, 111, 11430-11436 (2007).

https://doi.org/10.1021/jp0751530

[53] Barkigia K. M., Miura M., Thompson M. A., Fajer J.: Models of photosynthetic chromophores: Molecular structure of the bacteriochlorin (2,3,12,13-tetrahydro5,10,15,20-tetraphenylporphinato)(pyridine)zinc(II). Inorganic Chemistry, 30, 2233-2236 (1991). https://doi.org/10.1021/ic00009a052

[54] Barkigia K. M., Fajer J., Spaulding L. D., Williams G. J. B.: Crystal and molecular structure of the isobacteriochlorin: (2,3,7,8-tetrahydro-5,10,15,20-tetraphenylporphinato)(pyridine)zinc(II) benzene solvate. Journal of the American Chemical Society, 103, 176-181 (1981). https://doi.org/10.1021/ja00391a031 